\title{
Model Predictive Control for the New Reduced Multi-level Grid-Connected Converter
}

\author{
Maryam Sarbanzadeh ${ }^{1}$, Mohammad Ali Hosseinzadeh ${ }^{1}$, Ali Saleh ${ }^{2}$, Marco Rivera ${ }^{1}$ \\ Javier Munoz ${ }^{1}$, Patrick Wheeler ${ }^{3}$ \\ ${ }^{1}$ Faculty of Engineering, University of Talca, Curico, Chile \\ maryam_sarbanzadeh@yahoo.com; m.a_hosseinzadeh@yahoo.com; marcoriv@utalca.cl; jamunoz@utalca.cl \\ ${ }^{2}$ Faculty of Engineering, University of Sirjan, Sirjan, Iran \\ alisalehi282@yahoo.com \\ ${ }^{3}$ Faculty of Engineering, University of Nottingham, Nottingham, UK \\ pat.wheeler@nottingham.ac.uk
}

\begin{abstract}
Reduced multi-level converters have been presented to enhance the efficiency by reducing the number of components which lead to reducing the size, volume and cost of converters. Predictive control is an advanced control strategy that is implemented for control of multi-level converters due to many advantages of fast response, no need proportional gain and easy to implement. To achieve these results, this paper proposes a predictive current control technique for a singlephase reduced multi-level grid-connected converter. The proposed reduced converter is a general topology for cascaded multilevel converters that reduce the number of components and generates high number of levels than traditional multi-level configurations. The proposed topology is connected to a grid and model predictive control technique is applied to control of the grid current. The model predictive control is used in two cases for the proposed 15-level reduced converter and proposed 31-level cascaded multi-level converter. Finally, to validate of the proposed reduced multi-level converter and proposed model predictive control the simulation results are presented under MATLAB/Simulink platform for proposed both converters.

Index Terms-reduced multi-level converter; model predictive control; cascaded topology.
\end{abstract}

\section{INTRODUCTION}

Multi-level inverters/converters (MLIs/MLCs) are involved in power electronic applications such as a variable frequency drive, FACTS devices, UPS, Statcom, DVR, electrical vehicle, and renewable energy sources [1]-[3]. The renewable energy sources has different types such as a photovoltaic system, wind, Geothermal, Hydro, biomass, etc. The photovoltaic system stored sunlight energy by their panels in batteries as DC voltage, so the DC voltage has to converter into AC voltage. Therefore a power electronic converter is necessary for changing DC power to AC power. The conventional converters are two and three levels have some problems such as a high voltage rating on their switches, high total harmonic distrution (THD) magnitude, high switching frequency. Multilevel converters introduced to overcome these problems by increasing the power electronic devices in their configurations. Multi-level converters can generate high voltage levels with reducing THD magnitudes and share the input voltage on their power switches to overcome the stress of switches issues.
Basically, important types of industrial multi-level converters are Neutral Point Clamped (NPC), Flying Capacitor (FC) and Cascaded H-Bridge (CHB) multi-level converter topologies [4]-[6].

The conventional topologies have a series benefits and drawbacks. The drawbacks of FC and NPC converters are due to use of many diode clamped and many flying capacitors respectively, to generate more voltage levels. The CHB converter has many advantages than two other topologies and it can work in symmetrical or asymmetrical operation modes. In the symmetric configuration, all DC source are equal in magnitude and the asymmetric configurations have different DC source values. CHB converter is used for medium and higher voltages, while both NPC and FC topologies have some challenge in higher balancing voltage levels [7], [8].

In two last decades, many researchers worked on multilevel topologies configurations aspect of the designing in symmetrical and asymmetrical modes, control strategies, and their applications [9], [10]. In term of designing, some symmetric and asymmetric multi-level converter topologies with reduced the number of switches has been reported in [11]-[14] and in term of controlling, the researches have developed the conventional control methods such as pulse with modulation (PWM), space vector modulation (SVM), staircase modulation and adventured control strategy of predictive control [15]-[17].

Predictive control strategies are one of the most recent control methods in power electronics applications. Over the past few years, research into these control methods has increased dramatically due to the high power computing of microprocessors. Generally, the term "predictive control" is used for an algorithm that considers the model's system to predict the future behavior of the system and select the most appropriate control action based on an optimization criterion. The principle of predictive method is using the system models to predict the future behavior of the control variables. In fact, in this method, the system model is used and the reference values, which makes the error in the next sample to be zero, is determined [18]-[20]. In general, the predictive method has the following advantages: easy-to-understand, ability to use in 
different types of systems like as power electronics converters, active filters, power factor correction, uninterrupted power supplies (UPS), DC to DC converters. Due to the use of the systems model in predictive control method, the performance of these methods depends on the accuracy of the model parameters such as the inductance of the filter. Therefore, the error in the model parameters make the system delays and reduces the performance so that the system becomes unstable. Dependence on model parameters is the most important defect in predictive control methods [21].

In this paper, in the first, a new reduce multi-level converter is introduced that generate high voltage levels. Then a cascaded connection is extended based on new topology. After that, the mathematical model of the converter and load are extracted. In next section, the predictive current control is applied to a new reduced multi-level converter for grid application in both cases reduced topology and proposed cascaded topology. Finally, the simulation results are investigated in two case studies for a 16-level reduced proposed converter and for a 31-level cascaded topology under MATLAB/Simulink platform.

\section{Reduced Multi-Level Converter}

\section{A. Packed U-Cell Converter}

The power circuit of the Packed U-Cell converter (PUC) which it has been presented in [14] is shown in Fig. 1. The PUC converter consists of six power switches and two DC sources which generates a 5-level of $0, \pm V 1, \pm 2 V 1$ in symmetric state and 7-level of $0, \pm V_{1}, \pm V 2, \pm\left(V 1+V_{2}\right)$ in the asymmetric state.

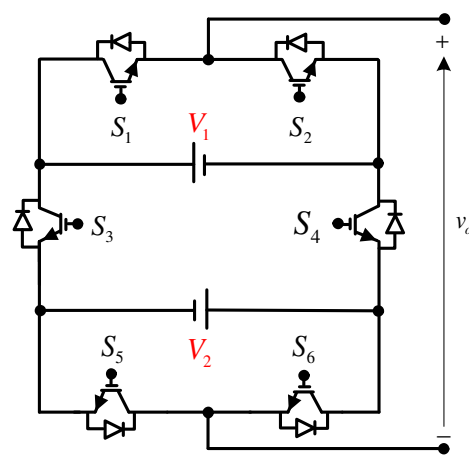

Fig. 1: PUC topology.

\section{B. Proposed 15-level Converter}

In order to achieve a high voltage levels, a reduced converter is designed based on modified PUC topology. The power circuit of the reduced converter is displayed in Fig. 2. The reduced topology is a PUC topology with two extra DC sources, two extra power switches, and two extra power diodes. Therefore, the numbers of power switches and DC source are increased eight and four which can generate a high voltage level at the output. In the proposed reduced converter, three DC sources of $V_{1}, V_{2}$ and $V_{3}$ can be combined to each other for creating positive voltage levels and $V_{4}$ is generates more negative voltage levels and it can combine with $V_{1}$ and $V_{2}$ like as $V_{3}$ and DC sources of $V_{3}, V_{4}$ cannot combine with each other. Table I gives the all possible switching states and output voltages of reduced converter topology. The proposed reduced converter can generate 7-level when the magnitudes of all DC sources are chosen the same values $\left(V_{1}=V_{2}=V_{3}=V_{4}=V_{d c}\right)$ and it can generate 15-level in asymmetric mode when the magnitudes of DC sources are chosen $\left(V_{1}=V_{d c}, V_{2}=2 V_{d c}, V_{3}=V_{4}=4 V_{d c}\right)$.

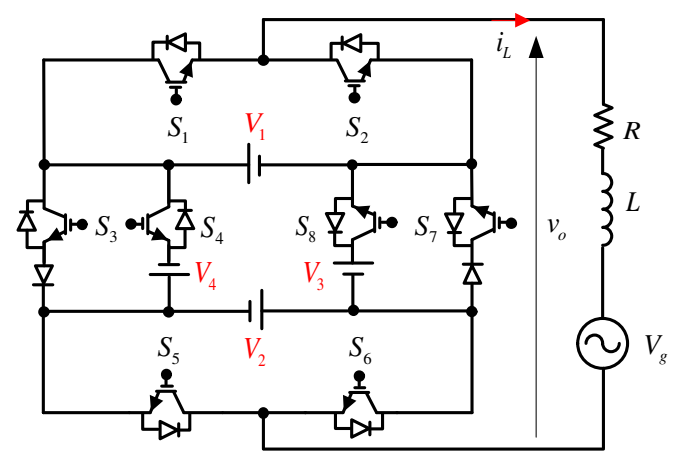

Fig. 2: Proposed reduced topology.

TABLE I: All Switching States of the Proposed Converter

\begin{tabular}{cccc}
\hline States & On Switches & Output Voltage & $\mathbf{V}_{o}$ \\
\hline \hline 1 & $S_{2}, S_{6}, S_{8}$ & $V_{1}+V_{2}+V_{3}$ & $+7 V_{d c}$ \\
2 & $S_{1}, S_{5}, S_{8}$ & $V_{2}+V_{3}$ & $+6 V_{d c}$ \\
3 & $S_{2}, S_{5}, S_{8}$ & $V_{1}+V_{3}$ & $+5 V_{d c}$ \\
4 & $S_{2}, S_{6}, S_{8}$ & $V_{3}$ & $+4 V_{d c}$ \\
5 & $S_{1}, S_{5}, S_{7}$ & $V_{1}+V_{2}$ & $+3 V_{d c}$ \\
6 & $S_{2}, S_{5}, S_{7}$ & $V_{2}$ & $+2 V_{d c}$ \\
7 & $S_{1}, S_{6}, S_{7}$ & $V_{1}$ & $+V_{d c}$ \\
8 & $S_{1}, S_{3}, S_{5}$ & 0 & 0 \\
9 & $S_{2}, S_{6}, S_{7}$ & 0 & 0 \\
10 & $S_{2}, S_{3}, S_{5}$ & $-V_{1}$ & $-V_{d c}$ \\
11 & $S_{1}, S_{3}, S_{6}$ & $-V_{2}$ & $-2 V_{d c}$ \\
12 & $S_{2}, S_{3}, S_{6}$ & $-\left(V_{1}+V_{2}\right)$ & $-3 V_{d c}$ \\
13 & $S_{1}, S_{4}, S_{5}$ & $-V_{4}$ & $-4 V_{d c}$ \\
14 & $S_{2}, S_{4}, S_{5}$ & $-\left(V_{1}+V_{4}\right)$ & $-5 V_{d c}$ \\
15 & $S_{1}, S_{4}, S_{6}$ & $-\left(V_{2}+V_{4}\right)$ & $-6 V_{d c}$ \\
16 & $S_{2}, S_{4}, S_{6}$ & $-\left(V_{1}+V_{2}+V_{4}\right)$ & $-7 V_{d c}$ \\
\hline \hline
\end{tabular}

\section{31-level Cascaded Converter}

The cascaded multi-level converters create high number of levels using low devices as well as they generate a lower THD's magnitude. So, the proposed reduced converter is developed to create more voltage levels based on cascaded two units of the proposed converter. In this case, the output voltage is the sum of the output voltages of the first and second unit. The proposed cascaded topology has $16^{2}$ switching states with a high redundancy switching states. In order to generate 31-level, the magnitude of DC sources are chosen based on the following method. The DC sources values for the first unit are considered as follow:

$$
V_{1,1}=V_{2,1}=V_{3,1}=V_{4,1}=V_{d c}
$$


The number of levels in the first unit are 7-level with three positive, three negative and zero levels and DC source values for the second unit are considered as follows:

$$
V_{1,2}=V_{d c}=V_{2,2}=V_{3,2}=V_{4,2}=4 V_{d c}
$$

The number of level in the second unit are the same with first unit but DC source magnitude are four times of first unit. Therefore, the second unit generates 7-level with higher magnitudes than the first unit. The output voltage of the proposed cascaded topology is obtained by the sum of the first and second unit output voltage levels that it generates 31-voltage level.



Fig. 3: Power circuit of 31-level cascaded converter.

\section{Model Predictive Control}

In order to implement a predictive control to current control of the grid, the mathematical model for proposed topologies of 15-level reduced and 31-level cascaded topology are derived. Therefore, the output voltage of the proposed converters are calculated to correspond to all possible switching states.

\section{A. Mathematical Model}

1) Mathematical Model of 15-level Converter: in the proposed 15-level converter (Fig. 4) with 16 possible switching states, the pair switches of $S_{1}, S_{2}$ and $S_{3}, S_{4}$ and $S_{5}, S_{6}$ and $S_{7}, S_{8}$ operate complementary. The output voltage of the proposed converter is the sum of voltages of on three switches of $S_{2}, S_{6}$ and $S_{7}$. So, the output voltage of the reduced converter according to the switching functions of power switches is expressed as follows:

$$
\begin{aligned}
V_{L, \text { sub }}= & S_{1} V_{1}+S_{5} V_{2}-\left(S_{3}-S_{7}\right)\left(V_{1}-V_{2}+V_{3}\right) \\
& -\left(S_{4}-S_{8}\right)\left(V_{1}-V_{2}+V_{3}+V_{4}\right)
\end{aligned}
$$

So, for the proposed 15-level converter with replacing of DC source magnitudes in the above equation, the output voltage of the converter is calculated as follows:

$$
V_{L, s u b}=\left(S_{1}-3 S_{3}-7 S_{4}+2 S_{5}+3 S_{7}+7 S_{8}\right) V_{d c}
$$



Fig. 4: Proposed reduced 15-level grid-connected converter.

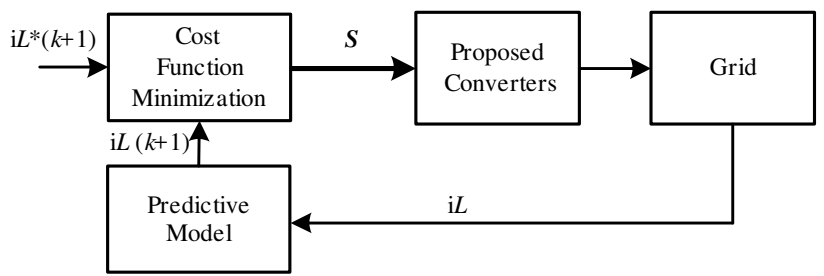

Fig. 5: Block diagram of predictive current control of proposed reduced converter.

Here, $V_{L, s u b}$ is, the generated output voltage by the proposed 15-level converter correspond to its switching functions.

2) Mathematical Model of 31-level Converter: The output voltage of the proposed 31-level cascaded topology is obtained based on the sum of the output voltage of each unit and equation (3). So the output voltage cascaded converter is:

$$
V_{L, c a s}=V_{o 1}+V_{o 2}
$$

The output voltage of first unit is obtained as follows based on equation (1) and (3):

$$
V_{o 1}=\left(S_{1,1}-S_{3,1}-2 S_{4,1}+S_{5,1}+S_{7,1}+2 S_{8,1}\right) V_{d c}
$$

The output voltage of second unit is obtained as follows based on equation (2) and (3):

$$
V_{o 2}=\left(S_{1,2}-S_{3,2}-2 S_{4,2}+S_{5,2}+S_{7,2}+2 S_{8,2}\right) V_{d c}
$$

Therefore, by replace of (6) and (7) in (5), the output of 31 -level cascaded topology respect on switching functions is calculated as:

$$
\begin{gathered}
V_{L, \text { cas }}=\left(S_{1,1}+4 S_{1,2}-S_{3,1}-4 S_{3,2}-2 S_{4,1}+8 S_{4,2}\right. \\
\left.+S_{5,1}+4 S_{5,2}+S_{7,1}+4 S_{7,2}+2 S_{8,1}+8 S_{8,2}\right) V_{d c}
\end{gathered}
$$

Here, $V_{L, \text { cas }}$ is, generated output voltage of the proposed 31-level cascaded converter. 
The mathematical model of proposed 15-level converter and proposed 31-level cascaded topology for grid-connected condition are obtained by following equations:

$$
\begin{aligned}
& V_{L}=R_{L} i_{L}+L \frac{d i_{L}}{d t}+V_{g} \\
& \frac{d i_{L}}{d t}=\frac{-R_{L} i_{L}+V_{L}-V_{g}}{L}
\end{aligned}
$$

Here, $V_{L}$ is output voltage generated by the proposed converts, $i_{L}$ is the load current and $V_{g}$ is grid voltage.

\section{B. Discrete-Time Model}

The discrete form of the load current of the converter for sampling time $T_{s}$ can be used to prediction current by measuring the voltage and load current at $k$.

$$
\frac{d i_{L}}{d t} \simeq \frac{i_{L}(k+1)-i_{L}(k)}{T_{s}}
$$

By replacing in the system equations, the current-load equation is obtained as follows:

$$
\left.i_{L}(k+1)=\left(1-\frac{R T_{s}}{L}\right) i_{L}(k)+\frac{T_{s}}{L}\left(V_{L}(k)-V_{g}\right)\right)
$$

The cost function of the predictive control for a current control objective will take the form:

$$
g=\left|i_{L}(k)-i_{L}^{*}(k)\right|
$$

The cost function is calculated for 15-level reduced topology and 31-level cascaded topology correspond to all possible switching states that they are 16 and 256256 switching states respectively.

\section{Simulation Results}

In order to validate model predictive control technique and designed controller two simulations for 15-level reduced converter and 31-level cascaded converter are presented on the MATLAB/Simulink environment. All parameters in the simulation study are given in Table II.

TABLE II: System Parameters

\begin{tabular}{ccc}
\hline Variable & Parameters & Values \\
\hline \hline$V_{d c}$ & DC link voltages & $60 \mathrm{~V}, 120 \mathrm{~V}, 240 \mathrm{~V}$ \\
$C_{i n}$ & DC Capacitors & $4700 \mu \mathrm{F}$ \\
$R_{L}$ & Line Resistive & $10 \Omega$ \\
$L_{L}$ & Line Inductance & $10 \mathrm{mH}$ \\
$V_{g}$ & Grid Voltage & $220 \mathrm{~V}$ \\
$T_{s}$ & Sampling Time & $10 \mu \mathrm{s}$ \\
\hline \hline
\end{tabular}

\section{A. Simulation Results of Proposed 15-level converter}

The simulation results of the proposed 15-level converter with the grid-connected condition are presented in this part. The number of DC-link voltage are four AC power sources with four rectifiers in order to charge four capacitors with different voltage values of $V_{C 1}=60 \mathrm{~V}, V_{C 2}=120 \mathrm{~V}, V_{3}=$ $V_{4}=240 \mathrm{~V}$. Therefore, the proposed topology generates 15 level. The simulation results of the proposed converter based on predictive current control are shown in Fig. 6. The grid voltage has the maximum peak $220 \mathrm{~V}$. The output voltage of the converter with a predictive control method consists of 15level with magnitudes of $0, \pm 60 \mathrm{~V}$ to $\pm 420 \mathrm{~V}$. The magnitude of the grid current waveform is $15 A$. Fig. 7 shows the THD's magnitude of the grid current which has a low value of $0.26 \%$ and it has a lower value than $5 \%$ IEEE-standard.
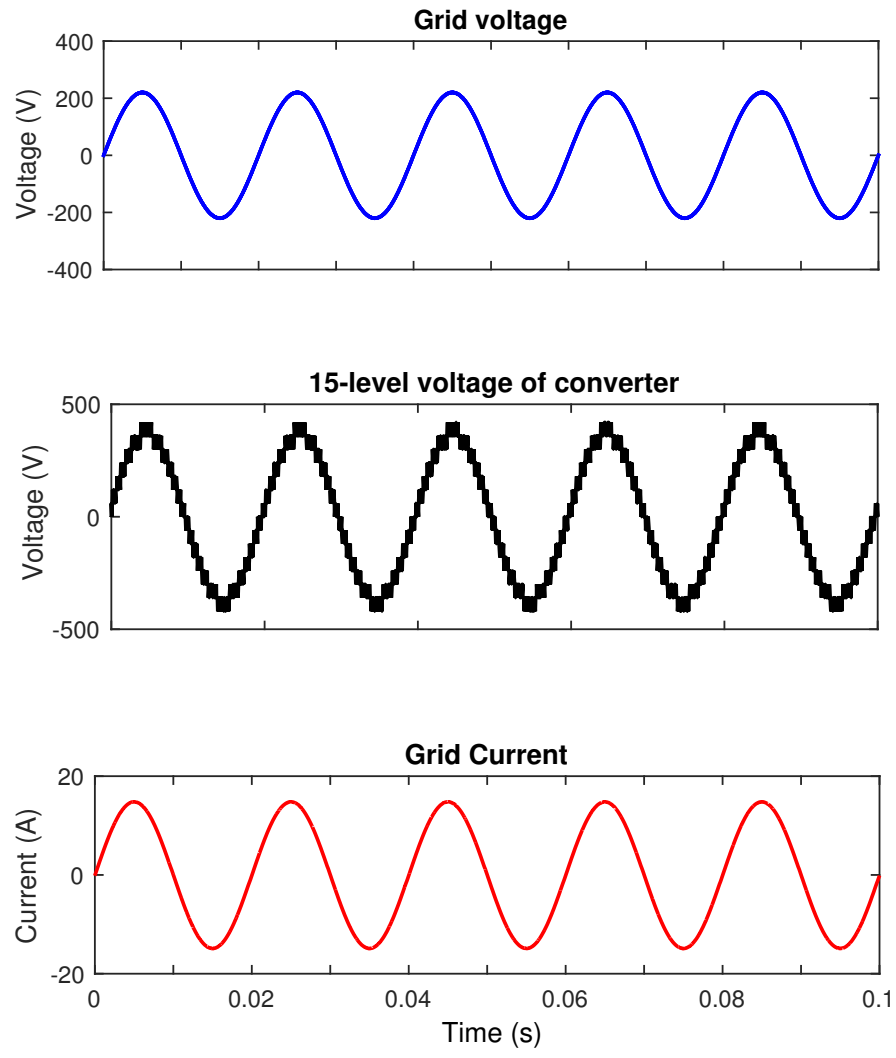

Fig. 6: Simulation results of grid-connected 15-level converter.

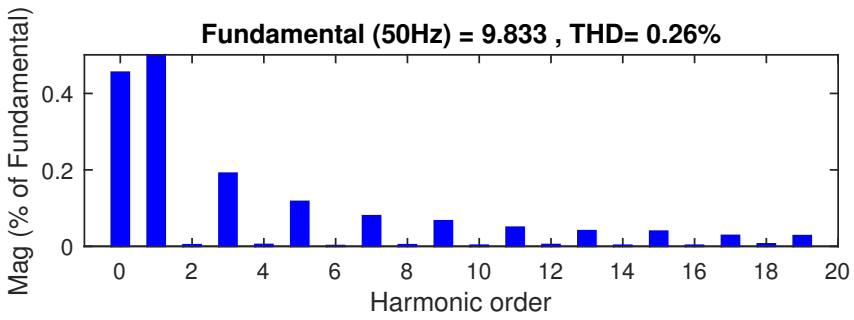

Fig. 7: FFT of grid current. 
Also, to evaluate the performance of control method the value of reference current is changed from $10 \mathrm{~A}$ to $15 \mathrm{~A}$ in $t>0.15$. As can see Fig. 8, the proposed predictive algorithm, controls the grid current very fast and tracks the reference current with the generated 15-level output voltage in the proposed converter.
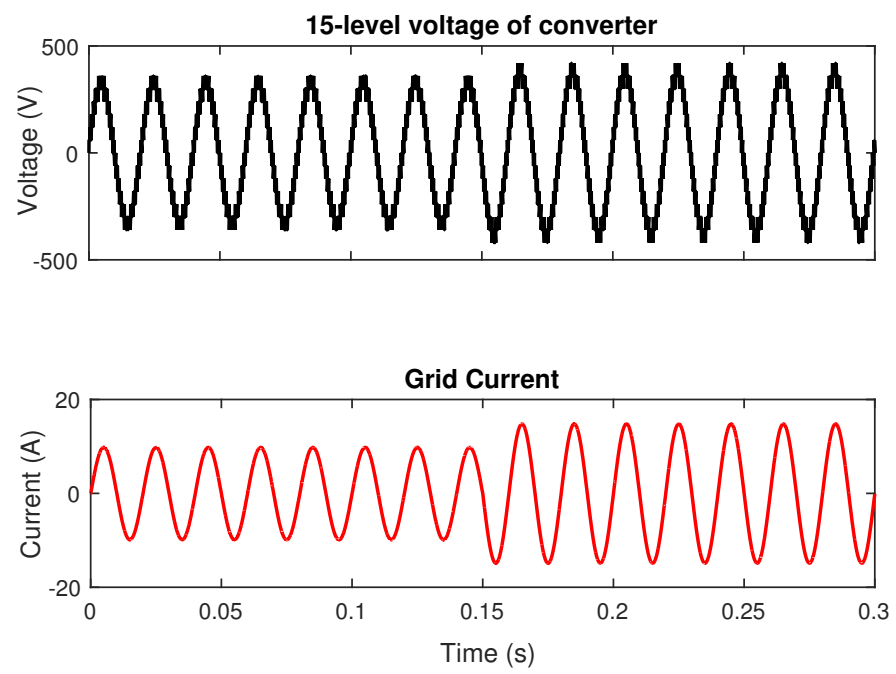

Fig. 8: Dynamic response of the output voltage of the 15-level converter and grid current.

\section{B. Simulation Results of 31-level Asymmetric Cascaded Topol- ogy}

To confirm the performance of cascaded topology based on the proposed predictive control method, the simulation results of the 31-level cascaded topology are presented. The 31level cascaded topology comprised of two proposed reduced converters. The values of DC capacitors voltage are chosen correspond to proposed methods (section II) which they have values: $V_{C 1,1}=V_{C 2,1}=V_{C 3,1}=V_{C 4,1}=25 \mathrm{~V}$ for the first unit and $V_{C 1,2}=V_{C 2,2}=V_{C 3,2}=V_{C 4,2}=100 \mathrm{~V}$ for the second unit. The proposed cascaded topology generates 31level with the peak of $375 \mathrm{~V}$ at the output.

The output voltage of each unit is 7-level with different forms and amplitudes (Fig. 9). The total output voltage of the proposed cascaded converter is obtained by sum the output voltage of the first and second unit are 31-level. Fig. 10 shows the THD's magnitude of the grid current which has not any THD's magnitude and it reconfirms the proposed control strategy with reducing harmonics. In addition, to evaluate the performance of control methods for proposed 31-level cascaded convector the value of reference current is increased from $10 A$ to $15 A$ in $t>0.15$ similar condition with the 15 level converter. As can see Fig. 11, the proposed predictive algorithm, controls the grid current very fast and tracks the reference current by increasing voltage levels to 31-level and it generates all desired voltage levels that proposed cascaded converter have to generate by the proposed DC source values.
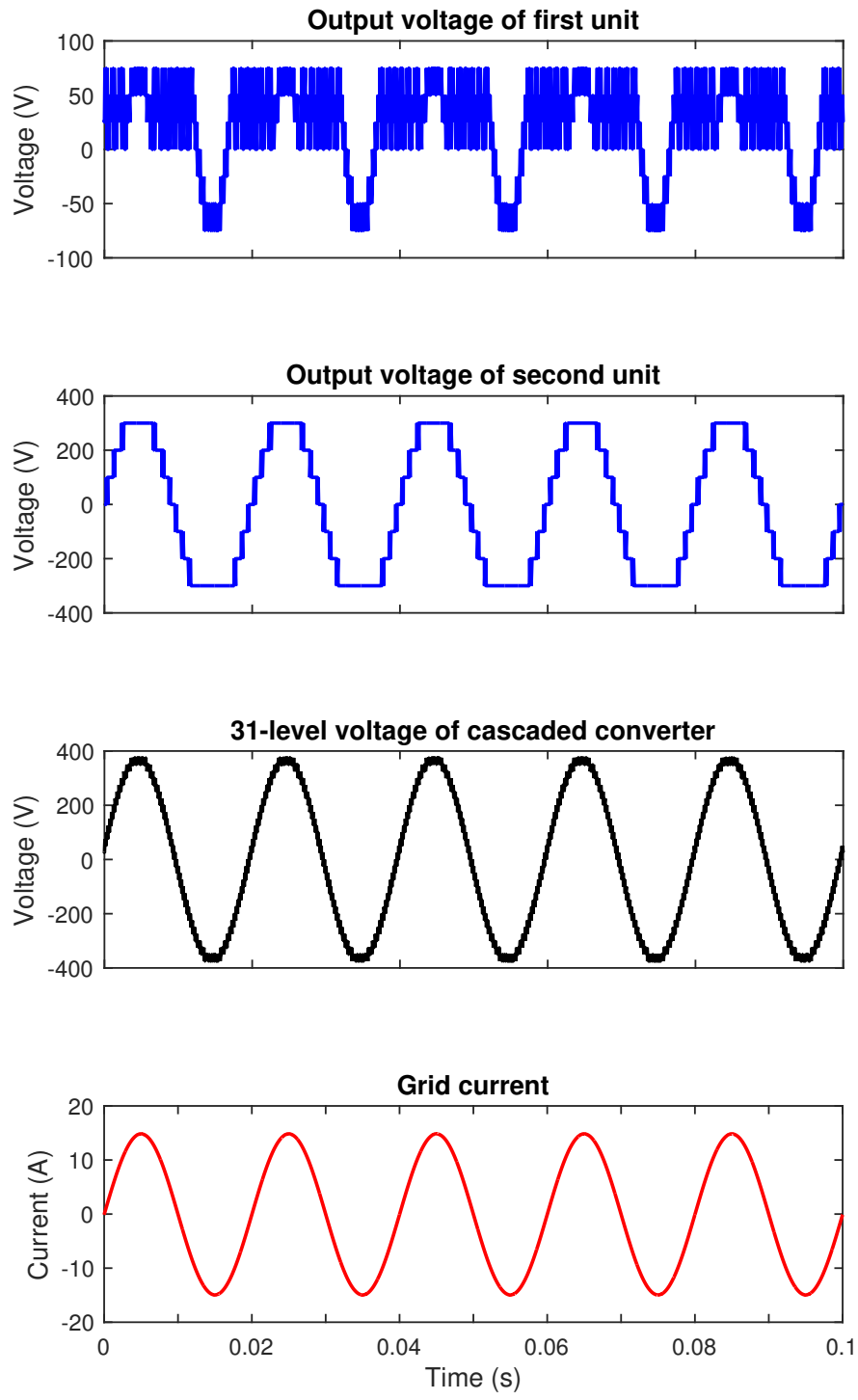

Fig. 9: Simulation results of 31-level grid-connected cascaded topology.

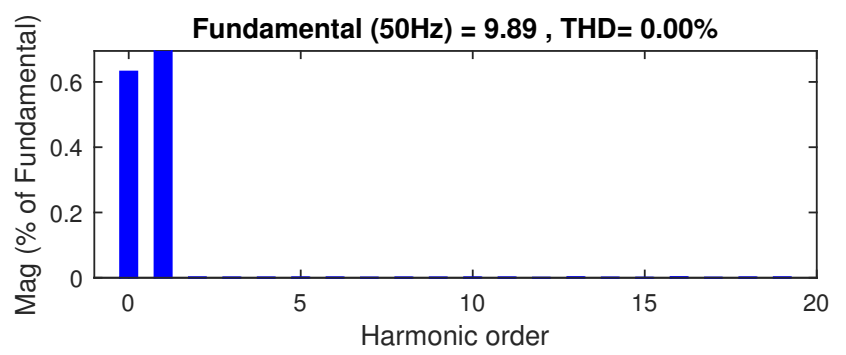

Fig. 10: FFT grid current for cascaded topology

\section{CONClusion}

In this paper, a new reduced multi-level converter was presented for grid-connection applications. The proposed reduced topology is a modified Packed U-Cell Converter (PUC) that generates double levels by extra two power switches and two DC sources than PUC. The proposed reduced converter 

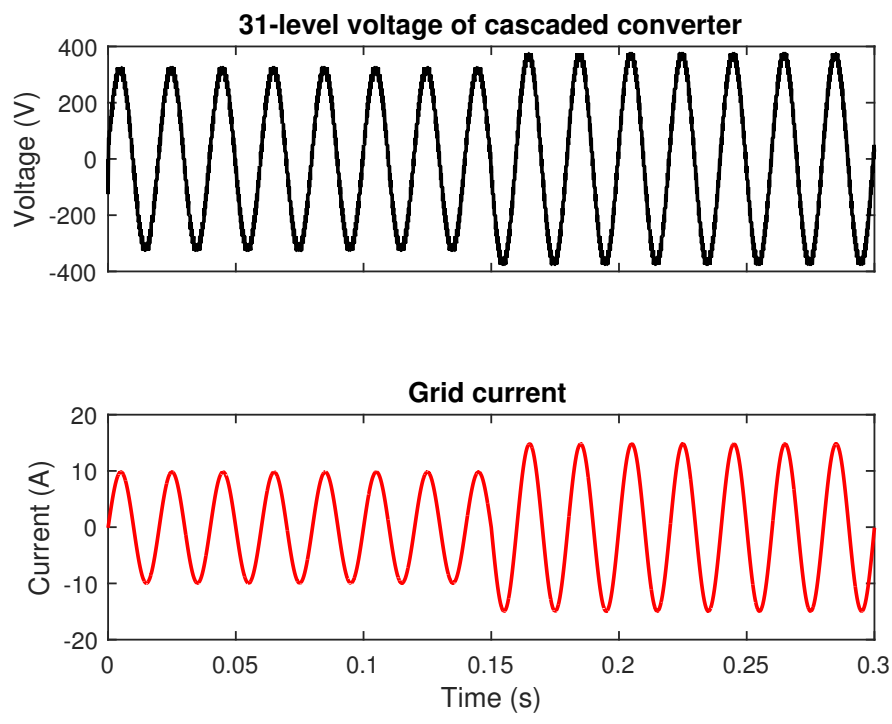

Fig. 11: Dynamic response of the output voltage of 31-level cascaded converter and grid current.

generates 15-level and a cascaded connection consists of two proposed reduced topologies that generated 31-level at the output to the reduced number of components and THD's amplitude. Both proposed topologies control by model predictive control method in grid-connection mode to control the grid current. The simulation results demonstrated the following results by the proposed model predictive control:

1. All voltage levels in proposed converters generated exactly.

2. Injected current to the grid was controlled in references values by proposed converters.

3. The converters had good dynamic responses with changing reference current amplitudes and tracked the reference currents very fast.

4. The THD's magnitude for 15-level proposed converter was $0.26 \%$ and for proposed 31-level cascaded converter was zero which reconfirms the proposed predictive current control technique.

Finally, the proposed topologies are good options for renewable energy applications such as wind and solar systems.

\section{ACKNOWLEDGMENT}

The authors wish to acknowledge the financial support of FONDECYT Regular 1160690 Research Project.

\section{REFERENCES}

[1] A. Mortezaei, M. G. Simes, T. D. C. Busarello, F. P. Marafo and A. Al-Durra, "Grid-Connected Symmetrical Cascaded Multilevel Converter for Power Quality Improvement," in IEEE Transactions on Industry Applications, vol. 54, no. 3, pp. 2792-2805, May-June 2018.

[2] A. Abdelhakim, P. Mattavelli, G. Spiazzi, "A Very high resolution stacked multilevel inverter topology for adjustable speed drives," IEEE Trans. Ind. Electron., vol. 65, no. 3, pp. 2049-2056, Mar. 2018.

[3] Y. Neyshabouri and H. Iman-Eini, "A New Fault-Tolerant Strategy for a Cascaded H-Bridge Based STATCOM," in IEEE Transactions on Industrial Electronics, vol. 65, no. 8, pp. 6436-6445, Aug. 2018.
[4] R. K. Varma and E. M. Siavashi, "Enhancement of Solar Farm Connectivity with Smart PV Inverter PV-STATCOM,' in IEEE Transactions on Sustainable Energy: doi: 10.1109/TSTE.2018.2862405.

[5] H. Li, Y. Zeng, B. Zhang, Q. Zheng, R. Hao and Z. Yang, ”An Improved H5 Topology with Low Common-mode Current for Transformerless PV Grid-connected Inverter," in IEEE Transactions on Power Electronics: doi: 10.1109/TPEL.2018.2833144.

[6] E. Z. Bighash, S. M. Sadeghzadeh, E. Ebrahimzadeh and F. Blaabjerg, "Adaptive Harmonic Compensation in Residential Distribution Grid by Roof-Top PV Systems," in IEEE Journal of Emerging and Selected Topics in Power Electronics: doi: 10.1109/TPEL.2018.2848359

[7] V. Dargahi et al., "Fundamental Circuit Topology of Duo-ActiveNeutral-Point-Clamped, Duo-Neutral-Point-Clamped, and DuoNeutral-Point-Piloted Multilevel Converters," in IEEE Journal of Emerging and Selected Topics in Power Electronics: doi: 10.1109/JESTPE.2018.2859313.

[8] D. Floricau, C. Popescu, M. Popescu, E. Floricau and L. Spataru, ”A comparison of efficiency for three-level NPC and Active NPC voltage source converters," 2009 Compatibility and Power Electronics, Badajoz, 2009, pp. 331-336.

[9] C. Dhanamjayulu and S. Meikandasivam, "Implementation and Comparison of Symmetric and Asymmetric Multilevel Inverters for Dynamic Loads," in IEEE Access, vol. 6, pp. 738-746, 2018.

[10] T. D. C. Busarello, A. Mortezaei, H. K. M. Paredes, A. Al-Durra, J. A. Pomilio and M. G. Simes, "Simplified Small-Signal Model for Output Voltage Control of Asymmetric Cascaded H-Bridge Multilevel Inverter," in IEEE Transactions on Power Electronics, vol. 33, no. 4, pp. 35093519, April 2018.

[11] M. Saeedian, M. E. Adabi Firouzjaee, S. M. Hosseini, J. Adabi and E. Pouresmaeil, "A Novel Step-Up Single Source Multilevel Inverter: Topology, Operating Principle and Modulation," in IEEE Transactions on Power Electronics: doi: 10.1109/TPEL.2018.2848359.

[12] M. Norambuena, S. Kouro, S. Dieckerhoff and J. Rodriguez, "Reduced Multilevel Converter: A Novel Multilevel Converter With a Reduced Number of Active Switches," in IEEE Transactions on Industrial Electronics, vol. 65, no. 5, pp. 3636-3645, May 2018.

[13] N. Sandeep, R.Y. Udaykumar, "Design and implementation of active neutral-point-clamped nine-level reduced device count inverter: an application to grid integrated renewable energy sources," IET Power Electron., vol. 11, no. 1, pp. 82-91, Feb. 2018.

[14] Y. Ounejjar, K. Al-Haddad, and L. A. Dessaint, "A Novel Six-Band Hysteresis Control for the Packed U Cells Seven-Level Converter: Experimental Validation," IEEE Transactions on Industrial Electronics, vol. 59, no. 10, pp. 3808-3816, 2012.

[15] K. Wang, Z. Zheng and Y. Li, "A Novel Carrier-Overlapped PWM Method for Four-Level Neutral-Point Clamped Converters," in IEEE Transactions on Power Electronics: doi: 10.1109/TPEL.2018.2833148.

[16] R. Ahmadi, M. Aleenejad, H. Mahmoudi and S. Jafarishiadeh, "FaultTolerant Space Vector Modulation for Modular Multilevel Converters with Bypassed Faulty Submodules," in IEEE Transactions on Industrial Electronics.doi: 10.1109/TIE.2018.2860518.

[17] M. Srndovic, A. Zhetessov, T. Alizadeh, Y. L. Familiant, G. Grandi and A. Ruderman, "Simultaneous Selective Harmonic Elimination and THD Minimization for a Single-Phase Multilevel Inverter With Staircase Modulation," in IEEE Transactions on Industry Applications, vol. 54, no. 2, pp. 1532-1541, March-April 2018.

[18] S. Vazquez, J. Rodriguez, M. Rivera, L. G. Franquelo and M. Norambuena, "Model Predictive Control for Power Converters and Drives: Advances and Trends," in IEEE Transactions on Industrial Electronics, vol. 64, no. 2, pp. 935-947, Feb. 2017.

[19] S. C. Ferreira, R. B. Gonzatti, R. R. Pereira, C. H. da Silva, L. E. B. da Silva and G. Lambert-Torres, "Finite Control Set Model Predictive Control for Dynamic Reactive Power Compensation With Hybrid Active Power Filters," in IEEE Transactions on Industrial Electronics, vol. 65 , no. 3, pp. 2608-2617, March 2018.

[20] R. Baidya, R. P. Aguilera, P. Acua, S. Vazquez and H. d. T. Mouton, "Multistep Model Predictive Control for Cascaded H-Bridge Inverters: Formulation and Analysis," in IEEE Transactions on Power Electronics, vol. 33, no. 1, pp. 876-886, Jan. 2018.

[21] S. El Islam Remache and K. Barra, "Performance comparison among boost and multilevel boost converters for photovoltaic grid connected system using finite set model predictive control," 2018 9th International Renewable Energy Congress (IREC), Hammamet, 2018, pp. 1-6. 